\title{
OBSTETRIC ANAESTHESIA
}

\author{
Dr Antonette Warnakulasuriya \\ President, College of Anaesthesiologists of Sri Lanka 2008
}

I selected "Obstetric Anaesthesia" for my presidential address as it is very close to my heart, for I consider this as one of the most important aspects of Anaesthesia and intensive care in keeping with my theme for 2008 -New Frontiers in Anaesthesia and Critical Care.

Obstetric Anaesthesia has become a very important aspect in maternity care in Sri Lanka dating back to the year 1905 when the first obstetric anaesthetic was administered in the De Soysa Lying in Home which was a hospital dedicated for women, started on the $15^{\text {th }}$ of December 1879.

The first recorded obstetric anaesthetic was on the $19^{\text {th }}$ of January 1847 by James Young Simpson who used Di-Ethyl Ether to alleviate the pain of labour and delivery for a patient with a deformed pelvis.

At that time the church of Scotland condemned its use as it was contrary to god's will citing the book of Genesis in the Bible "in pain thou shall bring forth children".

Many eminent physicians of the day also opposed its use.

The popularity of Anaesthesia for labour and delivery was greatly accelerated in 1853 when John Snow administered chloroform to Queen Victoria for the birth of her $8^{\text {th }}$ child Prince Leopold and James Young Simpson assisted the delivery.

Simpson was among the first to view rationally the use of anaesthesia during childbirth.
Ether was the anaesthetic for labour and childbirth in the later part of the $19^{\text {th }}$ century.

Problems faced were, the risk of aspiration and asphyxia for mother and infant in untrained hands. Ether was used only by physicians and majority of births were home deliveries. At times when labour was prolonged actual administering was often left to the husband or some untrained bystander who happened to be available.
The role of the Obstetric Anesthetist
Is multifold,
1. In the antenatal period
2. Labour - Pain relief
3. Delivery - Vaginal Delivery \& operative delivery
4. High dependency care and Intensive Care
5. Education

\section{Antenatal Period}

During the antenatal period his/her services are needed to treat co existing diseases as these should be assessed in good time and managed by a multi disciplinary team. The patients who would have succumbed in the early days due to various congenital and acquired diseases, now grow up to childbearing age and beyond, thus subjecting the anaesthetist to challenges. This places an added burden on maternity care specially in our set up where numbers needing care is out of proportion to the beds that are available. With constant and vigilant care with intensive monitoring their lives are made safer. Obstetric anesthetist in close collaboration with other specialists - obstetrician, paediatrician, physician, can improve the quality of life of the mother thereby providing safe Obstetric Anaesthesia. 


\section{During Labour:}

Pain is such a constant feature in the reproductive process that it has been looked upon as inevitable. The relief of pain is looked upon as an important human endeavor in every field of activity except Obstetrics. Most of the mothers in labour have inadequate pain relief and more likely none at all. Efforts have been made from early times to relieve the pain and anguish associated with labour and various methods have been employed according to the customs of the time.

In ancient Egypt, priests were summoned to invoke the aid of religion and God. Herbs and potions were commonly used amongst primitive people. Hippocrates instructed the midwives to relive the pain at childbirth but they were not effective owing to the limited therapeutic means at their disposal. Various remedies from black magic to anaesthetic agents have been employed from time to time.

Anaesthesia abolishes the pain as well as consciousness. It also robs the mother of the thrilling experience and the joy of motherhood.

Analgesia while abolishing the pain retains consciousness which would enable her to experience to the full the pleasurable sensation associated with the arrival of her baby.

Read's Technique: Grantly Dick Read maintained that in normal labour, fear is the chief pain producing factor and eliminating fear can be achieved by developing confidence and faith.

Hypnosis - has been used in midwifery for quite a long time. Repeated suggestions can remove that element of fear.

Acupuncture, Hydrotherapy and Aromatherapy are some of the other methods adopted.

TENS - Transcutaneous Electrical Nerve Stimulation are also methods that have been used. Drugs - Ideal analgesic drugs should relieve pain without any harmful effect on the mother or the fetus.

It should not interfere with uterine contractions.
It should be easily administered. Patient should sleep between pain but arouse during pain.

All drugs known to relieve pain of labour, except local anaesthetics depress the fetus to a greater or lesser extent and search for the ideal drug still continues.

Drugs that have been used are Potassium Bromide and Chloral, Morphine and Scopalamine.

In 1907 Richard Von Steinbuchal, an Austrian physician described the method of "Twilight Sleep" by using the above drugs.

The drugs in common use today are

- Pethidine- In Sri Lanka this is a widely used drug especially in maternity units where sophisticated methods of pain relief cannot be used due to constrains in skilled staff, drugs and monitoring facilities.

- Inhalational Agents - Chloroform, Ether, Entonox, Trilene have been used. Records show that Chloroform was used in The De Soysa Lying - in - home for caesaerean section in the year 1905 by Dr. Sinnathamby. Only 2 Caesarean sections were done that year. (Until recently GA was often administered even for vaginal deliveries).

- Barbiturates - Not used widely as it has no analgesic effect but only sedative action.

- Local Anaesthetics - This plays a very important role in obstetric practice. In the early days popularity varied but there has been a marked swing towards local anaesthetics in recent years. It is mainly due to the mother's request to be awake during Caesarean section for the birth of the baby.

1. Local infiltration - Blocking the pudendal nerve as it lies on the ischeal spine abolish the pain in late second stage

2. Epidural, Caudal - repeated or continuous injection of LA drugs to extradural space. Excellent analgesia and highly desirable as the block can be extended in the event of an emergency operative delivery. Usefulness is limited as it requires expertise and highly trained nursing personal for its administering purposes with added monitoring facilities. This though the best 
method at present cannot be used in all our maternity units due to the above constraints.

\section{Operative delivery}

Before 1960 operative delivery was carried out under Chloroform or Ether anaesthesia without tracheal intubation.

In 1946 - Curtis Mendelson a New York Obstetrician, described the syndrome of pulmonary aspiration of gastric contents in obstetric patients undergoing General Anaesthesia - which was named the MENDELSON'S SYNDROME

With the increase in caesarian section rate, the problem of aspiration continued to be a major concern. The Mendelson Syndrome was minimized by series of changes in the practice of obstetric anaesthesia.

The technique of rapid sequence induction, involving preoxygenation, cricoid pressure, use of succinyl choline and avoidance of mask ventilation prior to tracheal intubation was developed.

In addition limiting oral intake during labour will prevent a full stomach.

The most effective method is to reduce gastric acidity during labour. This has been achieved by the wide spread use of drugs to prevent acid secretion in the stomach.

$\mathrm{H}_{2}$ blockers with sodium citrate to neutralize any gastric acid already present have been advocated.

With the advent of tracheal intubation to prevent acid aspiration another major problem arose that of failed intubation resulting in failed oxygenation and even ending up in death.

The risk was reduced by better training of anaesthetist, trained assistants to assist the anaesthetist and to apply cricoid pressure.

Failed intubation drill was described by Tungstall and Rosen in 1976.

Use of monitors such as capnography and oxymetry throughout induction, maintenance and recovery from anaesthesia decreased the morbidity associated with general anaesthesia.

Move towards regional anaesthesia led to a marked reduction in anaesthesia related maternal deaths. This also avoided the airway management problems. But a new problem has now emerged with the practice of regional anaesthesia. There is concern now over the lack of experience attained by some anaesthetists and their lack of confidence to deliver general anaesthesia for operative delivery when required.

In 1942, German obstetrician, Rolf Hansen first noted the potential dangers of supine position in late pregnancy. $\mathrm{He}$ described the 'supine hypotension syndrome' in late pregnancy.

In 1968, Caldeyro Barcia described aorta-iliac compression where blood flow to the uterus is decreased leading to fetal acidosis. Every measure must be taken to avoid this. Specially when transporting patients to wards, to operating theater and also while placing them on the operating table. Achieving 15 degrees of left lateral tilt can reduce the pressure exerted by the gravid uterus on the inferior vena cava.

\section{Castle Street Hospital for Women}

\begin{tabular}{|c|c|c|c|c|c|c|}
\hline & 2001 & 2002 & 2003 & 2004 & 2005 & 2006 \\
\hline Deliveries & 16912 & 17359 & 17069 & 16358 & 17607 & 18533 \\
\hline LSCS & 4760 & 5350 & 5949 & 5571 & 6314 & 6601 \\
\hline $\begin{array}{l}\text { LSCS } \\
\text { Rate }\end{array}$ & $28.1 \%$ & $31.1 \%$ & $34.9 \%$ & $34.0 \%$ & $35.9 \%$ & $35.6 \%$ \\
\hline Epidural & 720 & 788 & 830 & 818 & 915 & 922 \\
\hline GA & 160 & 172 & 186 & 178 & 115 & 230 \\
\hline Spinal & 3880 & 4390 & 4933 & 4575 & 5284 & 5449 \\
\hline $\begin{array}{l}\text { Maternal } \\
\text { Deaths }\end{array}$ & 10 & 14 & 10 & 6 & 11 & 8 \\
\hline $\begin{array}{l}\text { Maternal } \\
\text { Death } \\
\text { Rate/ } \\
1000 \\
\text { deliveries }\end{array}$ & 0.6 & 0.8 & 0.6 & 0.4 & 0.6 & 0.2 \\
\hline
\end{tabular}

\section{The Present situation in Sri Lanka}

$10 \%$ of all deliveries in the country take place at the Castle Street Hospital in Colombo established in the year 1950. These are the statistics from Castle Street Hospital for 
women where I was involved in obstetric Anaesthesia and Critical Care from the year 2000.

Table 1

\begin{tabular}{|l|l|l|}
\hline Deliveries & Total & LSCS \\
\hline 2001 & 16912 & 4760 \\
\hline 2002 & 17359 & 5350 \\
\hline
\end{tabular}

Table 2

\begin{tabular}{|l|l|l|l|l|}
\hline Year & Deliveries & Epidural & GA & Spinal \\
\hline 2001 & Operation & 720 & 160 & 3880 \\
\hline 2002 & LSCS & 788 & 172 & 4390 \\
\hline & & & & \\
\hline
\end{tabular}

Table 3

\begin{tabular}{|l|l|l|}
\hline Deaths & Maternal & \\
\hline 2001 & 10 & $0.6 \%$ \\
\hline 2002 & 14 & $0.8 \%$ \\
\hline & & \\
\hline
\end{tabular}

As seen in the above statistics, more than $80 \%$ of caesarian sections were done under spinal anaesthesia, $10-15 \%$ under epidural anaesthesia, and less than 5\% were done under General anaesthesia.

Maternal mortality from all causes has decreased during the last decade. Shift towards regional techniques is one of the reasons. The maternal mortality was 0.4 to 0.8 per 1000 deliveries.

\section{Intensive care}

This is a vital requirement for complicated obstetric patients to reduce mortality. This improves the quality of care and will undoubtedly reduce morbidity and mortality drastically. Lack of intensive care leading to the death of a mother cannot be justified at this day and age. A readily available multidisciplinary team at the earliest hour will decide the fate of both mother and baby.

Intensive care should be started as soon as its need arises and should not wait for admission to an intensive care unit. Availability of specially trained staff and a suitably equipped area in the ward is all that's necessary until a bed is found in an intensive care unit. Availability of monitors with invasive and non-invasive facilities helps to detect the severity of the illness early. Early involvement of the intensive care consultant and the effective use of advanced support measures are useful in stabilizing the patient.

\section{Intensive Care Admissions - CSHW}

\begin{tabular}{|l|l|l|l|}
\hline Year & $\begin{array}{l}\mathbf{2 0 0 3} \\
\mathbf{3 3 0} \text { Ad }\end{array}$ & $\begin{array}{l}\mathbf{2 0 0 4} \\
\mathbf{3 3 6} \mathrm{Ad}\end{array}$ & $\begin{array}{l}\mathbf{2 0 0 5} \\
\mathbf{4 9 5} \mathrm{Ad}\end{array}$ \\
\hline $\begin{array}{l}\text { H' Age } \\
\text { APH }\end{array}$ & 48 & 49 & 81 \\
\hline PIH & 132 & 131 & 152 \\
\hline $\begin{array}{l}\text { Ht. } \\
\text { Dis. }\end{array}$ & 55 & 60 & 96 \\
\hline Help & 8 & 8 & 16 \\
\hline Eclam & 13 & 15 & 19 \\
\hline Rsp.dis & 17 & 12 & 20 \\
\hline Renal & 7 & 5 & 9 \\
\hline CNS & 4 & 3 & 4 \\
\hline $\begin{array}{l}\text { Miscellaneous+ } \\
\text { Gynae }\end{array}$ & 56 & 43 & 98 \\
\hline Trans & 71 & 64 & 96 \\
\hline
\end{tabular}

These are the statistics from the intensive care unit at Castle Street Hospital for women from 2003 to 2005. As seen from the data patients are transferred to this premier tertiary care hospital from all over the island.

The highest numbers of admissions are patients with Pregnancy Induced Hypertension.

When I commenced work in Obstetric Anaesthesia in 1981 Magnesium Sulphate was not in the therapeutic armamentarium in the management of Eclampsia. However it was introduced to Sri Lanka in the late 1980's.

Even as far back as 1941 there is a record of the use of $\mathrm{MgSO} 4$ in eclamptic patients.

In the Journal of the Ceylon branch of the British Medical Association - June 1941

Dr G A W Wickramasuriya - Visiting Obstetrician De Soysa Lying in Home mentioned in the article "Eclampsia in Ceylon. Use of Magnesium Sulphate in Eclampsia"

Dr.Wickramasuriya has also noted climatic variation as an etiological factor in the incidence of Eclampsia.

Incidence of septic abortion, puerperal sepsis and post operative infection has declined. 


\section{Education}

Greater educational efforts are required to establish safe practice by applying fundamentals of safe obstetric anaesthesia. As a professional college we have taken it upon our shoulders to be responsible for the proper training and education of our juniors.

In the Part 1A examination there is always a question set on safe obstetric anaesthetic practice.

For non career anaesthetists the certificate of competence examination carries a compulsory question on safe obstetric practice and also viva questions.

Even in the Basic science courses in physiology emphasis is given to physiological changes in pregnancy.

Part 11 examination which is the final component of the MD examination too lays emphasis on safe obstetric practice.

Not only education but attitudes too should be changed towards good and safe practice of obstetric anaesthesia. "The facts that could save lives in obstetrics has been available for many years but poor practice still abounds"

Training the junior staff and early consultant anaesthetists involvement is needed. Training must ensure competence in airway management, recognition and management of critically ill patient, invasive monitoring etc.
The use of guide lines and protocols are now the practice the world over. I am thankful to the Ministry of Health for giving the Colleges the opportunity to draw up National guidelines for the safe and better practice of obstetric anaesthesia in Sri Lanka

Good record keeping will help in future reference. This is a poorly practiced aspect in our country reason being the heavy workload. I personally think that this should not be made an excuse. If practiced from the very start it will develop as a habit.

Finally what is important is that every pregnancy ends in happiness - A happy mother, a healthy baby and ecstatic family.

A happy family will make a healthy and happy nation.

What better achievement do we need?

$* * * * * * * * * * * * * * * * * * * * * * * * * * * * * * * * * * * * * * * * * * * * * * * * * * * * * * * * * * * * * *$

THE COLLEGE OF ANAESTHESIOLOGISTS OF SRI LANKA

\section{LECTURE DEMONSTRATION \& CERTIFICATION}

\section{ON}

\section{Cardio Pulmonary Resuscitation}

$\begin{array}{ccc}\text { Venue } & & \text { Trauma Lecture Hall } \\ \text { Date } & \text { National Hospital, Sri Lanka } \\ \text { Time } & - & \text { on Tuesdays } \\ & 9.00 \text { am } \\ & \text { Conducted by } \\ & \text { Dr Shirani Hapuarachchi } \\ \text { Consultant Anaesthetist, NSU }\end{array}$

